\title{
THE GENETICAL RESPONSE TO NATURAL SELECTION BY VARIED ENVIRONMENTS
}

\section{SHORT-TERM OBSERVATIONS}

\author{
A. MINAWA* and A. J. BIRLEY \\ Department of Genetics, University of Birmingham, PO Box 363 , \\ Birmingham B15 2TT, England
}

Received 19.iv.77

\begin{abstract}
SUMMARY
In a large laboratory cage population of Drosophila melanogaster "Texas" 36 per cent of loci were found to be polymorphic and the average genic heterozygosity per individual was estimated at 8.2 per cent. Two large replicate subpopulations of "Texas" were established in each of three experimental environments which differed in their degree of environmental variability. The populations were sampled on two occasions, after 27 and after another 54 weeks. By the second sampling, statistical tests showed that the phenotypic distributions of all seven polymorphic loci studied had changed significantly. On the second occasion five loci had responded differently to the three environments and the remaining two loci showed significant changes of phenotype frequency between occasions. It was concluded from the rapidity of the changes that the observations were the result of intense natural selection. Hence the results did not agree with the neutral gene theory of protein evolution. The average genic heterozygosity of individuals was not directly related to the applied levels of environmental heterogeneity.
\end{abstract}

\section{INTRODUCTION}

The hypothesis of Kimura (1968) and Kimura and Ohta (1971) is that most protein polymorphisms have no adaptive value. Under their hypothesis the observed levels of genic heterozygosity $(H)$ are a function of effective population size, $\mathcal{N} e$ and $\mu$ the neutral mutation rate. This relationship is given at equilibrium by $\mathrm{H}=4 \mathcal{N} e \mu /(4 \mathcal{N} e \mu+1)$. Hence levels of genic heterozygosity can be expected to follow effective population size. Now estimates of genic heterozygosity from different populations of the same species are often similar. Under the neutral gene theory, genetical similarity will occur when there is only a very low migration rate between populations, in this case, however, $\mathcal{N} e$ will be the combined effective population size for all these populations. The observed values of genic heterozygosity are then lower than would be expected from their predicted relationship with $\mathcal{N} e$. Yet this result cannot be taken as evidence for anything but mild natural selection in protein polymorphisms; a development of the neutral gene theory (Ohta, 1974; Ohta and Kimura, 1974), assumes only very small deleterious effects in fitness for mutant alleles. The outcome of their model is a demonstration of consistency between estimates of effective population sizes and of genic heterozygosity obtained from natural populations; this is not surprising given our scanty knowledge of the mutation rates to neutral alleles and effective population sizes. An inadequate knowledge concerning

* Present address: Department of Social Medicine, Cancer Registry, University of Birmingham, Medical School, Birmingham B15 2TT, England. 
the magnitudes of such parameters will lead to a remarkable flexibility of conclusion. This is illustrated by Nei, Maruyama and Chakraborty (1975) who discuss the distributional data of Ayala (1972) which was obtained from populations of Drosophila willistoni and interpreted by the original author along selectionist lines. Nei et al. (1975), concluded that the data were compatible with the neutralist viewpoint, if the species was of recent origin. Thus with a suitable choice of values for $\mu$ and $\mathcal{N} e$ in the recent and geological past, these data do not contradict the neutralist theory; our knowledge of the actual values is too poor for a definite conclusion to be drawn.

An alternative approach is more direct and relies initially upon the response of different genetically determined variants to controlled laboratory situations. If natural selection does shape the gene-pools of populations then the first premise to be investigated is the generality of response to selection by the environment. In this respect there is experimental data. Powell (1971) demonstrated a striking positive and almost linear relationship between the average genic heterozygosity of individuals and the level of environmental heterogeneity imposed upon experimental populations of D. willistoni. McDonald and Ayala (1974) working with D. pseudoobscura demonstrated a similar although not so full a response as that obtained by Powell (1971). The rationale for such experiments is given by Ludwig (1950) and Mayr (1963). Some theoretical models concerned with the maintenance of genetical variation within populations (Levene, 1953; Haldane and Jayakar, 1963; Maynard-Smith, 1966; Hoekstra, 1975), show that although the conditions are restrictive, stable equilibria can be attained through selection in heterogeneous environments. In nature there is little doubt that environments are changeable and vary spatially. The response to selection by environmental variability with laboratory populations will provide a method for assessing the maintenance and behaviour of genetical variability within natural populations. We have carried out such an experiment with an established population of Drosophila melanogaster and the results presented here are a fuller presentation of those given in an earlier short paper (Minawa and Birley, 1975).

\section{Materials AND MEthods}

\section{(i) The population}

An established laboratory population of Drosophila melanogaster " Texas" was used. This population originated from a sample of 30 inseminated females which were captured at Austin, Texas, in 1965. Details of the maintenance of this population are described by Barnes and Kearsey (1970). The population size is about 3000 adults. The ratio of effective to actual population size has been estimated as 0.82 (M. J. Kearsey, personal communication).

\section{(ii) The subpopulations}

Six subpopulations of "Texas" were independently and expeditiously established within 3 weeks, so that they would all be approximately the same age. The setting up of the subpopulations involved the transfer of 2000 adults (as equal numbers of male and female flies) to each cage. These adults were obtained from samples of eggs which had been taken from the 
"Texas" population. The subpopulations were assigned at random to three experimental environments, a, b and c; a pair of cages to every environment. The population cages used were of the same design as that used for the "Texas" population. Details of this design may be obtained from Barnes (1968). The nature of the three experimental environments was as follows: (a) the temperature was alternated, that is between $18^{\circ}$ and $25^{\circ}$ and then back again to $18^{\circ}$ etc. A change of temperature was carried out every 3 days. The food medium consisted of oatmeal, agar, molasses, live bakers' yeast, raisins and sultanas. (b) These populations were kept at $-15^{\circ}$ for 30 minutes every 3 days; otherwise at $25^{\circ}$ (this treatment was sufficient to stun but not to kill the adult population), the food medium being the same as for (a). (c) The food medium consisted of agar, sucrose, and dried bakers' yeast and the population was maintained at a constant temperature of $25^{\circ}$. Thus environments (a) and (b) contained more variables than did (c).

\section{(iii) Sampling}

The subpopulations were sampled on two occasions, in August 1973, and again in August 1974. This was accomplished by the withdrawal of two vials containing fresh medium covered with eggs from every replicate cage population. The medium in a vial was then sectored and apportioned between four culture bottles. These bottles again contained the food medium corresponding to the sampled cages. Emergent adults from the culture bottles were collected, pooled and aged for 2-3 days under low density conditions. If the generation interval in a population cage with overlapping generations is about 3 weeks (Barker, 1962), then the populations were sampled after nine and again after about 18 generations.

\section{(iv) Genetical polymorphism and starch gel electrophoresis}

Horizontal starch gel electrophoresis was carried out on individual flies from the "Texas" cage population in January 1973. Of the 24 loci investigated, eight were found to be polymorphic. They were, Esterase-6 (Est-6), Octanol dehydrogenase $(O d h)$, Alcohol dehydrogenase $(A d h)$, $\alpha$-Glycerophosphate dehydrogenase $(\alpha-G p d h), 6$-Phosphogluconate dehydrogenase $(6-P g d h)$, Leucine aminopeptidases A and D, (Lap-A and Lap-D) and Phosphoglucomutase $(P g m)$. In addition to these eight polymorphic enzyme loci, the population was also polymorphic for the major mutant pink $(\mathrm{p})$. The latter is an eye-colour mutant and is recessive to the wild-type allele. Hence nine out of the 25 loci, i.e. 36 per cent, of the loci studied in "Texas" were polymorphic. The average heterozygosity per individual, calculated from the average of the unweighted heterozygote proportions was 8.2 per cent. Gel electrophoresis was carried out on an 11 per cent starch (Connaught Medical Laboratories, Toronto) gels. The Poulik (1957) buffer system was used to type individuals at the Est-6,Adh, Odh, $\alpha-G p d h$, $L a p-A$ and $L a p-D$ loci. The $6-P g d h$ locus was resolved with the histidinecitrate discontinuous buffer system of Fildes and Harris (1966), the Pgm locus by the methods of Spencer, Hopkinson and Harris (1964). Genotypes at the polymorphic pink locus were ascertained from the progeny of individual backcrosses to a line homozygous for the pink allele. 


\section{Results}

Preliminary studies showed that two of the polymorphic loci, Lap-A and $P g m$ were for technical reasons unsuitable for this study. The level of enzyme activity at the $L a p-A$ locus was apparently low, so that the locus was unsuitable for any large scale experiment which required consistent and unambiguous classification of enzyme phenotypes. The second locus, Pgm showed a tri-allelic polymorphism in "Texas", rare alleles having the very low frequencies of 0.01 and 0.03 . Since the bases for this experiment were comparisons amongst phenotype frequencies, assessment for the $\mathrm{Pgm}$ locus in terms of efficiency was not worth while in practice. For these reasons, $P g m$ and $L a p-A$ were not included in this study.

\section{(i) Phenotype frequencies}

Natural selection can be detected from changes or variations amongst the phenotypic arrays of polymorphic loci. There are three main sources of such variation in the results of this experiment, (a) between environments, (b) over time-i.e. between samplings, and (c) between replicate populations from the same environment and sampling time. Differences in the phenotypic distributions at a locus in cases (a) and (b) significantly larger than those found for (c) are evidence for natural selection. Factors which contribute to the variation between replicate populations are four-fold: $(w)$ variation between the samples of eggs taken from the "Texas" population and subsequently used to form the subpopulations, $(x)$ variation amongst the samples of eggs taken from the subpopulations at the two sampling times, $(y)$ variation due to random genetic drift during the course of the experiment and $(z)$ variation generated when the form of any natural selection differed in two apparently similar replicate cages, for example as a result of the critical environmental selection occurring in temporally different sequences (Lewontin, 1967).

A contingency $\chi^{2}$-test for 2 degrees of freedom was used as a test for homogeneity between the phenotype frequencies of replicate populations (table 1). The Lap-D locus was assayed on occasion 2 only. There are then 39 such $\chi_{(2)}^{2}$ values. Three of these were statistically significant, i.e. corresponded to a probability of 0.05 or less. With so many $\chi^{2}$-values this could be a reflection of chance alone. For a large number of values the mean $\bar{\chi}^{2}=n$, where $n$ is the average number of degrees of freedom. These are shown below in table 2. The values of $\bar{\chi}^{2}$ correspond closely to $n$ (i.e. 2); hence possibly the three aberrant $\chi_{(2)}^{2}$ values reflect random variables. If so, differences between replicate cages are attributable to variation type $(x)$ only, variations types $(w),(y)$ and $(z)$ being of negligible importance. However, it seems safer not to make this presumption but to rely on the following procedure which gives an unequivocal test for the presence of natural selection.

A test of whether the variation in phenotype frequencies was greater between environments than between replicate populations was carried out as follows. If $\chi_{\mathrm{A}}^{2}$ and $\chi_{\mathrm{B}}^{2}$ are two independently distributed $\chi^{2}$ values with degrees of freedom d.f.A and d.f.B respectively, then by definition $\left(\chi_{\mathrm{A}}^{2} /\right.$ d.f. $\left._{\mathrm{A}}\right) /\left(\chi_{\mathrm{B}}^{2} /\right.$ d.f. $\left._{\mathrm{B}}\right)$ is a variance ratio with d.f. $\mathrm{A}$ and d.f. . W With the pooled 
TABLE 1

Phenotypic frequencies and $\chi^{2}$-values for $2 d . f$. of homogeneity between replicate populations

\begin{tabular}{|c|c|c|c|c|c|c|c|c|c|}
\hline \multirow[b]{2}{*}{ Locus } & \multirow{2}{*}{$\begin{array}{l}\text { Population } \\
\text { environment }\end{array}$} & \multicolumn{3}{|c|}{$\begin{array}{l}\text { Occasion 1 } \\
\text { Mobility classes }\end{array}$} & \multirow[b]{2}{*}{$\chi_{(2)}^{2}$} & \multicolumn{3}{|c|}{$\begin{array}{c}\text { Occasion } 2 \\
\text { Mobility classes }\end{array}$} & \multirow[b]{2}{*}{$\chi_{(2)}^{2}$} \\
\hline & & $1 / 1$ & $1 / 2$ & $2 / 2$ & & $1 / 1$ & $1 / 2$ & $2 / 2$ & \\
\hline Est-6 & $\begin{array}{l}\mathrm{a}_{1} \\
\mathrm{a}_{2} \\
\mathrm{~b}_{1} \\
\mathrm{~b}_{2} \\
\mathrm{c}_{1} \\
\mathrm{c}_{2}\end{array}$ & $\begin{array}{r}73 \\
72 \\
74 \\
38 \\
107 \\
79\end{array}$ & $\begin{array}{l}56 \\
58 \\
55 \\
26 \\
27 \\
24\end{array}$ & $\begin{array}{r}11 \\
10 \\
8 \\
6 \\
9 \\
2\end{array}$ & 0.61 & $\begin{array}{l}154 \\
130 \\
106 \\
111 \\
126 \\
171\end{array}$ & $\begin{array}{r}84 \\
84 \\
82 \\
93 \\
113 \\
160\end{array}$ & $\begin{array}{r}17 \\
7 \\
12 \\
10 \\
11 \\
13\end{array}$ & 0.51 \\
\hline Odh & $\begin{array}{l}a_{1} \\
a_{2} \\
b_{1} \\
b_{2} \\
c_{1} \\
c_{2}\end{array}$ & $\begin{array}{l}5 \\
4 \\
8 \\
5 \\
2 \\
0\end{array}$ & $\begin{array}{l}27 \\
33 \\
27 \\
18 \\
10 \\
17\end{array}$ & $\begin{array}{l}83 \\
68 \\
70 \\
45 \\
52 \\
53\end{array}$ & $\begin{array}{l}1.01 \\
2.97\end{array}$ & $\begin{array}{l}3 \\
5 \\
6 \\
4 \\
0 \\
2\end{array}$ & $\begin{array}{l}77 \\
39 \\
17 \\
31 \\
49 \\
79\end{array}$ & $\begin{array}{l}178 \\
189 \\
191 \\
165 \\
195 \\
253\end{array}$ & $2 \cdot 05$ \\
\hline pink & $\begin{array}{l}a_{1} \\
a_{2} \\
b_{1} \\
b_{2} \\
c_{1} \\
c_{2}\end{array}$ & $\begin{array}{r}65 \\
154 \\
102 \\
54 \\
64 \\
72\end{array}$ & $\begin{array}{l}24 \\
68 \\
35 \\
21 \\
13 \\
18\end{array}$ & $\begin{array}{l}4 \\
4 \\
3 \\
2 \\
0 \\
2\end{array}$ & $\begin{array}{l}2 \cdot 07 \\
0 \cdot 19\end{array}$ & $\begin{array}{l}147 \\
178 \\
176 \\
145 \\
152 \\
194\end{array}$ & $\begin{array}{l}54 \\
55 \\
77 \\
55 \\
30 \\
40\end{array}$ & $\begin{array}{r}7 \\
11 \\
11 \\
3 \\
1 \\
1\end{array}$ & $\begin{array}{l}0.99 \\
3.31 \\
0.05\end{array}$ \\
\hline$A d h$ & $\begin{array}{l}a_{1} \\
a_{2} \\
b_{1} \\
b_{2} \\
c_{1} \\
c_{2}\end{array}$ & $\begin{array}{r}105 \\
51 \\
168 \\
49 \\
107 \\
54\end{array}$ & $\begin{array}{l}30 \\
14 \\
38 \\
19 \\
30 \\
15\end{array}$ & $\begin{array}{l}5 \\
5 \\
1 \\
2 \\
3 \\
1\end{array}$ & $5 \cdot 51$ & $\begin{array}{l}212 \\
196 \\
166 \\
140 \\
197 \\
277\end{array}$ & $\begin{array}{l}40 \\
46 \\
59 \\
46 \\
49 \\
61\end{array}$ & $\begin{array}{l}3 \\
3 \\
9 \\
6 \\
2 \\
2\end{array}$ & $\begin{array}{l}0.94 \\
0.27\end{array}$ \\
\hline$\alpha-G p d h$ & $\begin{array}{l}a_{1} \\
a_{2} \\
b_{1} \\
b_{2} \\
c_{1} \\
c_{2}\end{array}$ & $\begin{array}{r}12 \\
21 \\
8 \\
5 \\
3 \\
10\end{array}$ & $\begin{array}{l}24 \\
36 \\
36 \\
19 \\
56 \\
41\end{array}$ & $\begin{array}{l}55 \\
89 \\
96 \\
46 \\
76 \\
89\end{array}$ & $0 \cdot 21$ & $\begin{array}{r}6 \\
11 \\
8 \\
8 \\
6 \\
6\end{array}$ & $\begin{array}{l}54 \\
49 \\
61 \\
49 \\
56 \\
94\end{array}$ & $\begin{array}{l}168 \\
179 \\
195 \\
144 \\
186 \\
238\end{array}$ & $\begin{array}{l}1.80 \\
0.47\end{array}$ \\
\hline 6Pgdh & $\begin{array}{l}a_{1} \\
a_{2} \\
b_{1} \\
b_{2} \\
c_{1} \\
c_{2}\end{array}$ & $\begin{array}{l}42 \\
44 \\
42 \\
41 \\
88 \\
42\end{array}$ & $\begin{array}{l}18 \\
19 \\
21 \\
22 \\
51 \\
57\end{array}$ & $\begin{array}{l}9 \\
5 \\
6 \\
7 \\
1 \\
1\end{array}$ & $0 \cdot 10$ & $\begin{array}{l}182 \\
151 \\
168 \\
156 \\
141 \\
203\end{array}$ & $\begin{array}{l}68 \\
90 \\
85 \\
67 \\
38 \\
49\end{array}$ & $\begin{array}{r}8 \\
11 \\
11 \\
6 \\
3 \\
4\end{array}$ & 1.50 \\
\hline$L a p-D$ & $\begin{array}{l}a_{1} \\
a_{2} \\
b_{1} \\
b_{2} \\
c_{1} \\
c_{2}\end{array}$ & & & & & $\begin{array}{l}125 \\
117 \\
134 \\
109 \\
127 \\
152\end{array}$ & $\begin{array}{l}75 \\
71 \\
73 \\
68 \\
47 \\
44\end{array}$ & $\begin{array}{l}15 \\
13 \\
13 \\
16 \\
11 \\
10\end{array}$ & 1.29 \\
\hline
\end{tabular}

TABLE 2

Mean $\chi^{2}$ values from replicate populations

$\begin{array}{lcc}\text { Sampling date } & n & \bar{\chi}^{2} \\ \text { August 1973 } & 2 & 1 \cdot 624 \\ \text { August 1974 } & 2 & 2 \cdot 168\end{array}$


phenotypic frequencies from replicate populations a series of $\chi^{2}$-values for 4 d.f. were calculated as a measure of the heterogeneity in phenotypic frequencies between the three environments for each occasion separately. This set of $3 \times 3$ contingency $\chi^{2}$-values corresponding to each locus and occasion are shown in table 3 . It is seen that on occasion 1, only two loci, Est-6 and 6-Pgdh have responded differently to different environments. On occasion 2, however, all loci except $O d h$ and $\alpha$-Gpdh show a significantly different response to the different environmental treatments. As mentioned above, in the analysis of these results the measure $\chi_{\mathrm{A}}^{2}$ is by itself a valid and more powerful test of natural selection, provided that there are no significant differences between replicate populations; if there are then the variance ratio should be used. The use of the variance ratio test will tend to reduce the evidence for natural selection, when there are no statistically significant differences between the replicate populations. Hence, we are being conservative in our assessments. In practice, however, we reach the same conclusions on either method.

TABLE 3

$\chi^{2}$-values and variance ratios for comparisons between environments in phenotypic frequencies

\begin{tabular}{|c|c|c|c|c|c|c|}
\hline & \multicolumn{2}{|c|}{ Occasion 1} & \multicolumn{4}{|c|}{ Occasion 2} \\
\hline Locus & $\begin{array}{c}\text { Replicate } \\
\text { cages } \dagger \\
(6 \text { d.f.) }\end{array}$ & $\begin{array}{l}\text { Environments } \\
\text { (4 d.f.) }\end{array}$ & $\begin{array}{l}\text { Variance } \\
\text { ratio for } \\
4 \text { and } 6 \text { d.f. }\end{array}$ & $\begin{array}{c}\text { Replicate } \\
\text { cages } \\
\text { (6 d.f.) }\end{array}$ & $\begin{array}{c}\text { Environments } \\
\quad(4 \text { d.f. })\end{array}$ & $\begin{array}{l}\text { Variance } \\
\text { ratio for } \\
4 \text { and } 6 \text { d.f. }\end{array}$ \\
\hline Est-6 & $4 \cdot 25$ & $34 \cdot 38$ & $12 \cdot 13 * *$ & $4 \cdot 19$ & $13 \cdot 11$ & $4 \cdot 69 *$ \\
\hline$O d h$ & $4 \cdot 73$ & $9 \cdot 65$ & 3.06 n.s. & $17 \cdot 48$ & $11 \cdot 30$ & 0.97 n.s. \\
\hline pink & $4 \cdot 22$ & $7 \cdot 92$ & $2 \cdot 82$ n.s. & $4 \cdot 35$ & $30 \cdot 21$ & $10 \cdot 42 * *$ \\
\hline$A d h$ & $7 \cdot 04$ & $7 \cdot 24$ & 1.54 n.s. & $2 \cdot 06$ & $22 \cdot 41$ & $16 \cdot 32 * *$ \\
\hline$\alpha-G p d h$ & $7 \cdot 38$ & $21 \cdot 18$ & $4 \cdot 30$ n.s. & $4 \cdot 50$ & $4 \cdot 26$ & 1.42 n.s. \\
\hline $6-P g d h$ & $1 \cdot 61$ & $18 \cdot 59$ & $17 \cdot 32 * *$ & $9 \cdot 39$ & $29 \cdot 87$ & $4 \cdot 77^{*}$ \\
\hline$L a p-D$ & 一 & - & - & $2 \cdot 59$ & 19.09 & $11 \cdot 06 * *$ \\
\hline
\end{tabular}

If the loci show a similar unidirectional response to selection in the three environments, then the effects of selection will not be detected by the measure $\chi_{A}^{2}$ but could appear as a significant difference between occasions. We may note that the experiment was designed to minimise the effect of random genetic drift between the two sampling times (occasions). In this respect, population sizes remained relatively constant between occasions 1 and 2, and were of the order 2500-3000 adults. Population size was therefore large compared to the number of generations that elapsed between the sampling dates. Hence, random genetic drift will contribute little to the variation between replicate cages by occasion 2; any significant variation which does exist is more appropriately ascribed to sampling variation of type $(x)$. As before, however, we shall use the more conservative test. A variance ratio for 2 and 4 d.f. (table 4 ) was calculated for each locus and environment separately and used as a test of natural selection between occasions 1 and 2 . In this instance phenotypic frequencies were pooled 
from replicate populations with the same sampling date and a $\chi_{\mathrm{A}}^{2}$ value for each locus and environment was obtained from $2 \times 3$ contingency tables as a measure of homogeneity between occasions for particular loci. $\chi_{\mathrm{B}}^{2}$ is in this case the sum of the two $\chi_{(2)}^{2}$ values which were calculated upon occasions 1 and 2 and which measured homogeneity between phenotypic frequencies in replicate populations on a given occasion. The variance ratios show that there is now evidence of selection at both the $\alpha-G p d h$ and Odh loci. That is, all seven loci have responded to natural selection through environmental difference.

\section{TABLE 4}

$\chi^{2}$-values and variance ratios for comparisons between occasions in phenotypic frequencies

\begin{tabular}{|c|c|c|c|c|}
\hline Locus & Environment & $\begin{array}{l}\text { Replicate cages } \\
\text { (4 d.f.) }\end{array}$ & $\begin{array}{l}\text { Occasions } \\
\text { (2 d.f.) }\end{array}$ & $\begin{array}{l}\text { Variance ratio } \\
\text { for } 2 \text { and } 4 \text { d.f }\end{array}$ \\
\hline \multirow[t]{3}{*}{ Est- 6} & a & 3.56 & $5 \cdot 11$ & 2.87 n.s. \\
\hline & b & $1 \cdot 12$ & 0.91 & 1.63 n.s. \\
\hline & $\mathrm{c}$ & $3 \cdot 76$ & $48 \cdot 45$ & $25 \cdot 77 * *$ \\
\hline \multirow[t]{3}{*}{ Odh } & a & $14 \cdot 60$ & $5 \cdot 45$ & 0.75 n.s. \\
\hline & b & $2 \cdot 60$ & $14 \cdot 80$ & $14 \cdot 37 *$ \\
\hline & c & $5 \cdot 55$ & $2 \cdot 75$ & 0.99 n.s. \\
\hline \multirow[t]{3}{*}{ pink } & a & 3.06 & 3.09 & $2 \cdot 02$ n.s. \\
\hline & b & $3 \cdot 50$ & 1.03 & 0.59 n.s. \\
\hline & $\mathrm{c}$ & $2 \cdot 01$ & $1 \cdot 13$ & $1 \cdot 12$ n.s. \\
\hline \multirow[t]{3}{*}{$A d h$} & a & $2 \cdot 26$ & $10 \cdot 46$ & $9 \cdot 26^{*}$ \\
\hline & b & $5 \cdot 78$ & 6.06 & 2.09 n.s. \\
\hline & c & $1 \cdot 06$ & $2 \cdot 95$ & 5.57 n.s. \\
\hline \multirow[t]{3}{*}{$\alpha-G p d h$} & a & 1.92 & $28 \cdot 27$ & $29 \cdot 45 * *$ \\
\hline & b & 0.72 & $3 \cdot 49$ & $9 \cdot 70^{*}$ \\
\hline & $\mathrm{c}$ & $9 \cdot 25$ & $14 \cdot 91$ & 3.22 n.s. \\
\hline \multirow[t]{3}{*}{$6-P g d h$} & a & $7 \cdot 50$ & $9 \cdot 50$ & 2.53 n.s. \\
\hline & b & $1 \cdot 60$ & $8 \cdot 62$ & $10 \cdot 78 *$ \\
\hline & c & 1.54 & $27 \cdot 29$ & $35.45 * * *$ \\
\hline \multicolumn{5}{|c|}{$\begin{array}{rl}* & 0.05>\mathrm{P}>0.01 \\
* * & 0.01>\mathrm{P}>0.001 . \\
* * * & \mathrm{P}<0.001 . \\
\text { n.s. } & \text { Not significant. }\end{array}$} \\
\hline
\end{tabular}

\section{(ii) Genic heterozygosity}

If genic heterozygosity per se responds rapidly to the degree of environmental variability, the maximum response to selection will be shown on occasion 2. At this time genic heterozygosity can be expected to be greatest in the most variable environment. The percentage heterozygosities on occasion 2 are shown in Minawa and Birley, 1975. An analysis of variance (table 5) was carried out after the data had been transformed into arcsin values. A $\chi^{2}$-test of significance was provided by the ratio $\mathrm{SS} / \sigma^{2}$, where $\sigma^{2}$ is $820 \cdot 7 / n$, or, the binomial variance. The value of $n$ is given by the harmonic mean of the number of typed individuals at every locus. The analysis shows that the variation between replicate cages does not differ significantly from the binomial variance which may therefore be used for testing for the presence of interactions between loci and environments, these turned out to be statistically significant, again evidence for natural selection. This was so whether the comparison was between the more 
TABLE 5

Analysis of variance for percentage heterozygosity (after the arcsin transformation) on occasion 2

\begin{tabular}{|c|c|c|c|c|c|c|}
\hline Item & d.f. & S.S. & M.S. & $\chi^{2}$ & V.R. & $\mathrm{P}$ \\
\hline $\begin{array}{l}\text { Between loci } \\
\text { Between environments }\end{array}$ & 6 & $786 \cdot 8408$ & $131 \cdot 8408$ & $225 \cdot 35$ & & $<1 \%$ \\
\hline $\mathrm{a} v s . \mathrm{b}$ & 1 & $4 \cdot 8140$ & $4 \cdot 8140$ & & 0.5631 & n.s. \\
\hline $\begin{array}{c}(\mathrm{a}+\mathrm{b}) v s_{.} \mathrm{c} \\
\text { Fironments }\end{array}$ & 1 & $27 \cdot 6525$ & $27 \cdot 6525$ & & $0 \cdot 8361$ & n.s. \\
\hline $\begin{array}{r}\text { Environments } \times \text { loci } \\
\text { a vs. } \mathrm{b} \times \text { loci }\end{array}$ & 6 & $51 \cdot 2933$ & $8 \cdot 5489$ & $14 \cdot 69$ & & $2 \%$ \\
\hline$(\mathrm{a}+\mathrm{b})$ vs. $\mathrm{c} \times$ loci & 6 & $198 \cdot 4327$ & $33 \cdot 0721$ & $56 \cdot 83$ & & $<1 \%$ \\
\hline Replicate populations & 21 & $99 \cdot 9686$ & $4 \cdot 7604$ & $28 \cdot 63$ & & $12 \cdot 3 \%$ \\
\hline Binomial variance & $\propto$ & & $3 \cdot 4917$ & & & \\
\hline
\end{tabular}

variable environments ( $\mathrm{a} v s$. b) or between the variable $(\mathrm{a}+\mathrm{b})$ and the least variable environments (c). The observed loci, being chosen for technical reasons only are presumably a random sample of the genetical variation within "Texas". The statistically significant interaction variances were therefore used as an error variance to test for comparisons amongst the three environments. The average genic heterozygosities per individual are shown in table 6 . There is a suggestion of less heterozygosity in the least variable environment, but this is not statistically significant (see table 5). This result is in contrast to that obtained by Powell (1971) and McDonald and Ayala (1974).

TABLE 6

Average genic heterozygosities in the three environments on occasion 2

Environment Average genic heterozygosity

$\begin{array}{ll}\text { a } & 7.52 \\ \text { b } & 7.90 \\ \text { c } & 7.00\end{array}$

\section{Discussion}

In nature a population encounters a range of environments and specific changes, e.g. temperature, light and food source can affect the genetical composition of the population (Dobzhansky, 1970). Intuitively, diverse environments are likely to maintain relatively more genetical variability than more uniform ones. The response of genetical variations in enzymes and other proteins to different environments is critical for any experimental test of the neutral gene theory. In this respect there are two approaches, one which measures a gross response of the genetical variation in a random sample of such molecules to environmental change, and another which aims to show selection at particularly amenable loci (e.g. Gibson, 1970; Clarke, 1975; de Jong and Scharloo, 1976). Both methods are of value. The work presented here takes the former approach.

Our results have shown unambiguous and decided responses to selection within 27 generations at all of the seven loci which were studied. The loci responded to a series of three environments with substantial shifts of 
phenotype frequency. The average heterozygosity per individual was approximately the same in the three experimental environments, and this result is in contrast to previous observations (Powell 1971; McDonald and Ayala, 1974). Consider first of all the extent of the response to selection in terms of individual loci. This quantity is difficult to assess from the two works cited above. The most available data are those of $\mathrm{McD}$ Donald and Ayala (1974) whose published measurements represent the average values of heterozygosity for a number of different types of environment with the same level of heterogeneity; it is then difficult to determine the total number of loci which have responded to natural selection. A rough calculation of the variation between levels of environmental heterogeneity using the binomial variance as an error variance, showed that about eight of the 20 loci they studied responded to natural selection. Evidence suggestive of natural selection was also obtained by Berger (197I) at three chromosome II loci in Drosophila melanogaster and Sing, Brewer and Thirtle (1973), observed selection in four out of seven polymorphic loci in the same species. The approach of the latter authors utilised a small effective population size. Natural selection was detected as an effect of small population size upon observed genic heterozygosity populations than would be expected on the basis of random genetic drift. These experiments then provide evidence of natural selection at least in association with the polymorphic enzyme loci. Nevertheless, the selection response may equally be attributed to the effect of selection on unrecognised loci in linkage disequilibrium with the observed loci, in particular for those experiments where the population size was small, since in the latter case linkage disequilibrium can be generated by drift alone.

Consider an extreme case of genetical linkage; through chromosomal inversions. Non-random associations in nature between enzyme polymorphisms and chromosomal inversions have been described (Prakash and Lewontin, 1968; Mukai, Mettler and Chigusa, 1971; Mukai, Watanabe and Yamaguchin, 1974; Langley, Tobari and Kojima, 1974). On the other hand, Powell (1972) found no such association in his populations of D. willistoni and McDonald and Ayala (1974) stated that their populations of $D$. pseudoobscura carried inversion sequences only on chromosome II, and of the 20 loci studied, 17 were located on chromosome III. Calculations of average genic heterozygosity for these 17 loci only did not alter their conclusions. In "Texas" it is possible to extract all possible combinations of alleles from the closest linkage group on chromosome III, Est-6, Odh and pink and preliminary studies do not suggest that the loci studied are associated with any inversion sequences. However, even in the absence of inversions it is possible to conceive a case for the response to selection being through closely linked loci.

A neutral allele in gametic disequilibrium with a closely linked locus subject to selection can be carried along in a "hitch-hike" manner (Maynard-Smith and Haigh, 1974). Gametic disequilibrium in "Texas" may be the result of an initial founder effect in the original sample of 30 inseminated females which were captured from the wild, or even perhaps be representative on an ancestral disequilibrium in the natural population. The cage population "Texas" has been maintained in the laboratory for about 130 generations, and any initial disequilibrium between two selectively neutral loci or between a selectively neutral and a selected locus must 
be small or trivial except for cases of almost complete linkage. Hence any genetical change which is correlated with a change of the environment can be interpreted as follows. The genetical polymorphism may or may not be selectively neutral either in "Texas" or in the new environment. Faced with a new environment any change in the genetical composition at a locus will be a response of the locus per se provided it is in gametic equilibrium with other loci in "Texas". If this is not so then the locus in question may be selectively neutral in the new environment and subject to the " hitchhike" response. But strong gametic disequilibrium in "Texas" after 130 generations in a cage is itself evidence in favour of natural selection. In this respect one trigenic disequilibrium is known in "Texas" for the three chromosome III loci, Est-6, Odh and pink (Birley 1974). A study of the allele frequencies in the experimental environments described in this paper does not show a correlated response to selection. It is concluded that natural selection has acted upon the observed loci, or very tightly linked polymorphic loci. This latter conclusion necessitates that if our seven loci are neutral, natural selection has acted upon seven tightly linked loci. We cannot, of course, resolve the problem of hitch-hiking conclusively. Only if the mode of selection and genotypic fitnesses were defined for the locus causing the hitch-hike would it be possible to calculate a maximum recombination fraction over which the observed changes in genotypic frequency could be due to such a response. However, one point is clear, namely that the rapid changes we have observed must be due to extensive natural selection at the seven loci themselves or at seven linked loci; the genetical variation is not behaving in accordance with the neutralist expectation.

In our view, the problem of genetical linkage has not, so far, been answered from the alternative approach concerned with selection for enzyme activity. A knowledge of a particular aspect of an enzyme's biochemistry is sometimes used to understand the role of natural selection in relation to enzyme activity. Individuals with different electromorphs show correlated enzyme activity differences. When selection occurs between the electromorphs in the presence of enzyme substrate, the class of electromorph with the highest enzyme activity or apparent substrate utilisation, shows an increased fitness. This selection response must be measured in conjunction with controls containing the product of an enzyme reaction (de Jong and Scharloo 1976), to eliminate any effect of the genetical background upon fitness. Even here the response need not be directly related to the locus in question. Natural selection acts upon the enzyme phenotype in vivo. The electromorph represents an enzyme phenotype and the latter is the result of a structural gene product and any variation due to modifier loci. Modifier loci are described for several enzyme activities in Drosophila melanogaster for example, aldehyde oxidase (Courtright, 1967). Our understanding of the response to selection is once again subject to a knowledge of linkage relationships, this time between the structural locus and the modifier loci, and also to any genotype-environment interaction shown by the enzyme phenotype upon food media containing the enzyme substrate, which may modify the in vivo reactions. Rather than aim at the understanding of specific loci we have chosen to obtain insight into the generality of the response to selection. The result is that selective forces will predominate over random genetical drift for most of the genome. 
Finally, consider the response of average genic heterozygosity to various degrees of environmental diversity. An experiment which purports to demonstrate a causal relationship between these two variables must show that the relationship is stable over time. If balanced polymorphism is maintained through the occupation of different ecological niches, the phenotypic frequencies must demonstrably stabilise in the various niches. In addition all combinations of environmental factors should be represented. Otherwise there is a danger that absences of treatments could give rise to a misleading result. Given a multiply heterogeneous environment, genotypic fitnesses at a locus may bear no simple relationship to those observed in homogeneous environments; the observed increases in heterozygosity shown by McDonald and Ayala (1974) could be short-lived ascribably to a few transient polymorphisms in which particular alleles are en route to fixation in some specific environments. In the present experiment no attempt was made to simulate discrete heterogeneities in the environment. The lack of response in heterozygosity could be a reflection of the genetical variation in " Texas" which has been the subject of the stabilising forces of the laboratory environment for some years; that genetical variation concerned with the expected response to selection by environmental heterogeneity was fixed before the onset of the experiment. For a study of genetical diversity in relation to environmental diversity our experiment and possibly some others are preliminary.

The chief function of the experiment described here was to see if any of the variation in "Texas" would respond to natural selection; that it has shown evidence for natural selection illustrates the enormous value of the direct experimental approach in contrast to that shown from surveys of enzyme polymorphism. Given that environmental diversity is greater in nature than utilised in this experiment, natural selection should determine a substantial part of molecular evolution. Whether or not much of the genetical variation in nature is due to balanced polymorphism is another question. Indeed, fitnesses may be stochastic in their magnitudes due to local variations in the environment; such a system will tend to preserve genetical variability within populations (Karlin and Liebermann, 1974; Levikson and Karlin, 1975). It is concluded that the results of this experiment give no support for the neutral gene theory of protein evolution.

Acknowledgments.-Dr J. S. Gale is thanked for his continued interest in this work and for a critical reading of the manuscript. Dr A. Minawa acknowledges the financial support of a graduate training scholarship from Makerere University, Kampala, Uganda.

\section{REFERENCES}

AYALA, F. J. 1972. "Darwinian versus non-Darwinian evolution in natural populations of Drosophila". Proc. 6th. Berkeley Symp. Math. Statistics and Probability. Vol. V:211-236.

BARKER, J. S. F. 1962. The estimation of generation interval in experimental populations of Drosophila. Genet. Res., Camb., 3, 388-404.

BARNEs, B. W. 1968. Stabilising selection in Drosophila melanogaster. Heredity, 23, 433-442.

BARNES, B. W., \& KEARSEY, M. J. 1970. Variation for metrical characters in Drosophila populations. I. Genetic Analysis. Heredity, 25, 1-10.

BERGER, E. 1971. A temporal survey of allelic variation in natural and laboratory populations of Drosophila melanogaster populations. Genetics, 67, 121-136.

BIRLEY, A. J. 1974. Multilocus polymorphism and selection in a population of Drosophila melanogaster. I. Linkage disquilibrium on chromosome III. Heredity, 32, 122-127.

CLARKE, B. C. 1975. The contribution of ecological genetics to evolutionary theory: detecting $40 / 1-D$ 
the direct effects of natural selection on particular polymorphic loci. Genetics, 79, 101113.

Courtright, J. B. 1967. Polygenic control of aldehyde oxide in Drosophila. Genetics, 57, 25-39.

dobzhansky, тh. 1970. Genetics of the Evolutionary Process. Columbria University Press, New, York.

FILDES, R. A., AND HARRIS, H. 1966. Genetically determined variation of adenylate kinase in man. Nature, 209, 261.

Gibson, J. 1970. Enzyme flexibility in Drosophila melanogaster. Nature, 227, 959-960.

haldane, J. B. S. AND JAYAKar, S. D. 1963. Polymorphism due to selection of varying direction. F. Genet., 59, 237-242.

hoekstra, R. 1975. A deterministic model of cyclical selection. Genet. Res. Camb., 25, 1-15. De JONG, G. AND SCHARLOO, W. 1976. Environmental determination of selective significance or neutrality of Amylase variants in Drosophila melanogaster. Genetics, 84, 77-94.

KARLIN, S. AND LIEBERMAN, U. 1974. Random temporal variation in selection intensities: case of large population size. Theor. Pop. Biol., 6, 355-382.

KIMURA, M. 1968. The genetic variability maintained via finite population due to mutational production of neutral and nearly neutral isoalleles. Genet. Res. Camb., 11, 246-269.

KimURA, м. AND oHTA, т. 1971. Protein polymorphism as a phase of molecular evolution. Nature, 229, 467-479.

LANGLEY, C. H., TOBARI, Y. N., AND KOJMMA, K. 1974. Linkage disequilibrium in natural populations of Drosophila melanogaster. Genetics, 78, 921-936.

LEVENE, H. 1953. Genetic equilibrium when more than one ecological niche is available. Am. Nat., 87. 331-333.

LEVIKSON, B., AND KARLIN, s. 1975. Random temporal variation in selection intensities acting on infinite diploid populations. Diffusion method analysis. Theor. Pop. Biol., 8, 292-330.

LEWONTIN, R. C. 1967. The principal of historicity in evolution. In Mathimatical challenge to the Neo-Darwinian Interpretation of evolution. Wistar. Symp. Monogr., 5, 81-94.

LudwiG, w. 1950. Zur theorie de konkurrenz. Die annidation (Einnischung) als fünfter evolutionsfacktor. Neue. Ergeb. Probleme Zool. Klatt-Festschrift, 516-537.

MaYNARD-Smith, J. 1966. Sympatric speciation. Am. Nat. 100, 637-650.

maYNARD-SMItH, J., AND HaIGH, J. 1974. The hitch-hiking effect of a favourable gene. Genet. Res. Camb., 23, 23-25.

MAYr. E. 1963. Animal species and Evolution. Harvard University Press, Cambridge, Mass.

MCDONALD, J. F., AND AYALA, F. J. 1974. Genetic response to environmental heterogeneity. Nature, 250, 572-574.

miNAWA, A., AND BIRLEY, A. J. 1975. Genetical and environmental diversity in Drosophila melanogaster. Nature, 225, 702-704.

MUKAI, T., METTLER, L. E., AND CHIGUSA, S. I. 1971. Linkage disequilibrium in a local population of Drosophila melanogaster. Proc. Nat. Acad. Sci. U.S., 68, 1065-1069.

MUKAI, T., WATANABE, T. K. AND YAMAGUCH, o. 1974. The genetic structure of natural populations of Drosophila melanogaster. XII. Linkage disequilibrium in a large population. Genetics, 77, 771-793.

NEI, M., MARUYAMA, T., AND CHAKRABORTY, R. 1975. The bottleneck effect and genetic variability in populations. Evolution, 29, 1-10.

онтA, T. 1974. Mutational pressure as the main cause of molecular evolution and polymorphism. Nature, 252, 351-354.

OHTA, T., AND KIMURA, M. 1974. Simulation studies on electrophoretically detectable genetic variability in a finite population. Genetics, 76, 615-624.

POWELl, J. R. 1971. Genetical polymorphism in varied environments. Science, 174, 10351479.

POWELL, J. R. 1972. Genetic polymorphism and environment. Science, 176, 545.

POULIK, M. D. 1957. Starch gel electrophoresis in a discountinuous system of buffers. Nature, $180,1477-1479$.

PRAKASH, s., AND LEWONTIN, R. C. 1968. A molecular approach to the study of genic heterozygosity. III. Direct evidence of co-adaptation in gene arrangements of Drosophila. Proc. Nat. Acad. Sci. U.S., 59, 398-405.

SING, C. F. BREWER, G. J., AND THIRTLE, B. 1973. Inherited biochemical variations in Drosophila melanogaster: noise or signal? I. Single locus analyses. Genetics, 75, 381-404.

SPENCER, N., HOPKINSON, D. A., AND HARRIS, H. 1964. Phosphoglucomutase polymorphism in man. Nature, 204, 742-745. 